\title{
Geniposide reverses multidrug resistance in vitro and in vivo by inhibiting the efflux function and expression of P-glycoprotein
}

\author{
HEFEI HUANG ${ }^{1}$, XUENONG ZHANG $^{1}$, ZHIXIONG HUANG ${ }^{1}$, YE ZHANG ${ }^{1}$ and ZHIYONG ZHOU ${ }^{2}$ \\ ${ }^{1}$ Department of Pharmacy, Yichang Central People's Hospital, First Affiliated Hospital of China Three Gorges University; \\ ${ }^{2}$ Department of Pharmacy, Medical College of China Three Gorges University, Yichang, Hubei 443002, P.R. China
}

Received September 8, 2015; Accepted October 7, 2016

DOI: 10.3892/etm.2016.4011

\begin{abstract}
Geniposide is a water-soluble iridoid glucoside with anti-oxidant and anti-inflammatory biological functions. It has been indicated that geniposide may increase doxorubicin (DOX) accumulation in drug-resistant tumor cells. The present study aimed to investigate the resistance-reversing effect of geniposide in DOX-resistant cells and assess the underlying mechanisms of its action. The results revealed that geniposide itself weakly inhibited tumor cell growth. Furthermore, geniposide effectively reversed DOX resistance in a dose-dependent manner in human osteosarcoma DOX-resistant (MG63/DOX) cells. The action of geniposide was confirmed by increased accumulation of intracellular DOX detected in MG63/DOX cells. Notably, geniposide enhanced the efficacy of DOX against MG63/DOX cancer cell-derived xenografts in nude mice. To study the mechanism, intracellular accumulation of rhodamine 123 was measured using flow cytometry. At concentrations that reversed multidrug resistance (MDR), geniposide significantly downregulated P-glycoprotein (P-gp) expression. Therefore, geniposide reverses P-gp-mediated MDR by reducing the expression of P-gp and its transport function. The present study therefore indicated that geniposide may be administered in combination with conventional anti-neoplastic drugs to prevent MDR.
\end{abstract}

\section{Introduction}

Cytotoxic agents are useful and successful treatments for cancer (1). However, the efficacy of these treatments is unpredictable due to the ability of cancer cells to acquire resistance to various drugs. This phenomenon is known as multidrug resistance (MDR) and may severely impact the clinical outcomes of patients with cancer. Although various

Correspondence to: Dr Zhiyong Zhou, Department of Pharmacy, Medical College of China Three Gorges University, 8 University Road, Yichang, Hubei 443002, P.R. China

E-mail: in_bud@ctgu.edu.cn

Key words: geniposide, multidrug resistance, P-glycoprotein, tumor xenograft mechanisms have been described, such as the activation of detoxifying protein, which repairs drug-induced DNA damage and disruptions in apoptotic signaling pathways (2), it has been demonstrated that overexpression of P-glycoprotein (P-gp) is the primary cause of MDR (3). As the product of the ATP Binding Cassette Subfamily B Member 1 (ABCB1) gene, P-gp is a member of the ATP-binding cassette membrane transport protein superfamily and was initially characterized in multidrug-resistant Chinese hamster ovary cells (4). Furthermore, P-gp is a broad-spectrum drug efflux pump able to bind neutral or positively charged hydrophobic drug substrates and unilaterally transport intracellular drugs out of cells, consequently minimizing their intracellular concentrations to acquire drug resistance (5).

Over the past three decades, a range of P-gp inhibitors, including verapamil and tariquidar (XR9576), have been developed and evaluated in pre-clinical and clinical trials $(6,7)$. However, none of these compounds are clinically efficacious without causing major side effects. While the majority of these agents are able to reverse MDR in vitro, they fail to achieve clinical success due to their intrinsic toxicity or alteration of the pharmacokinetics of co-administered anti-cancer drugs (5). It has been demonstrated that the undesired effects of certain agents lead to the inhibition of the metabolism and elimination of certain anti-cancer drugs; thus their plasma concentrations increase, as do their associated toxic effects (8). Therefore, non-toxic MDR inhibitors that lack pharmacokinetic interactions with anti-cancer agents are required. Substances derived from natural products commonly used in Traditional Chinese Medicine have attracted considerable attention due to their lower toxicity compared with chemically synthesized substances (9). Geniposide is a water-soluble iridoid glucoside derived from the Gardenia jasminoides Ellis (Rubiaceae) that is used in Traditional Chinese Medicine. It has anti-oxidant $(10,11)$, anti-inflammatory $(12,13)$ and anti-thrombotic effects (14). Previous studies have indicated that geniposide may significantly inhibit the proliferation of K562/ADM-resistant tumor cells in a dose-dependent manner $(15,16)$. The combined administration of geniposide and doxorubicin (DOX) significantly increased DOX accumulation in the resistant cell lines, compared with administration of DOX alone (15). In the present study, the MG63/DOX cell line that overexpresses P-gp and its xenograft model characterized by DOX resistance, were used to identify whether 
geniposide was capable of reversing MDR mediated by P-gp in vivo; furthermore, the associated mechanisms of action were assessed.

\section{Materials and methods}

Drugs and reagents. DOX was obtained from Pfizer Italia Srl (Rome, Italy). Geniposide was obtained from the National Institute for the Control of Pharmacological and Biological Products (Beijing, China). Rhodamine 123 (Rho123), MTT assay and verapamil were purchased from Sigma-Aldrich, Merck Millipore (Darmstadt, Germany). Monoclonal antibodies against ABCB1 (ab3366) were purchased from Abcam, Ltd., (Hong Kong, China).

Cell lines and cell culture. The MG63 human osteosarcoma cell line and its MDR counterpart MG63/DOX were kindly provided by Dr Zan Shen (Department of Oncology, Affiliated Sixth People's Hospital, Shanghai Jiao Tong University, Shanghai, China). Cell lines were cultured in vitro as a monolayer culture in Dulbecco's modified Eagle's medium (DMEM) supplemented with $10 \%$ heat-inactivated fetal bovine serum (both Gibco; Thermo Fisher Scientific, Inc., Waltham, MA, USA), $100 \mathrm{U} / \mathrm{ml}$ penicillin and $100 \mathrm{mg} / \mathrm{ml}$ streptomycin at $37^{\circ} \mathrm{C}$ in a humidified atmosphere of $5 \% \mathrm{CO}_{2}$.

Assay of cytotoxicity and reversal effect in vitro. Cytotoxicity and the reversal effect of geniposide towards MG63/DOX cells were measured by MTT assay as previously described (17). MG63/DOX cells (103/well) were seeded in 96-well plates and allowed to attach for $12 \mathrm{~h}$. The cells were treated with various concentrations of geniposide $(6.25,12.5,25,50,100$ and $200 \mu \mathrm{mol} / \mathrm{l}$ ) for $72 \mathrm{~h}$. Cell viability was assessed following addition of $50 \mu \mathrm{l}$ MTT reagent $(5 \mathrm{mg} / \mathrm{ml})$ and incubation for $4 \mathrm{~h}$. MTT medium was subsequently removed and dissolution of the purple crystal was performed with $150 \mu$ l dimethyl sulfoxide. Light absorbance of the solution was measured at $570 \mathrm{~nm}$ using an iMark $^{\mathrm{TM}}$ microplate reader (Bio-Rad Laboratories, Inc., Hercules, CA, USA). Net absorbance from the plate of cells cultured with control medium (not treated) was considered to be $100 \%$ cell viability.

The reversal effect of geniposide was then investigated using the same method. The cells seeded in 96-well plates were treated with various concentrations of DOX $(9.38,1.56$, $0.260,0.0434,0.00723 \mu \mathrm{mol} / \mathrm{l})$ in the absence or presence of geniposide $(25,50$ and $100 \mu \mathrm{mol} / \mathrm{l})$ for $72 \mathrm{~h}$. The reversal fold (RF) values, were calculated using the following formula: $\mathrm{RF}=\mathrm{IC}_{50}$ of DOX alone $/ \mathrm{IC}_{50}$ of DOX in the presence of geniposide with $\mathrm{IC}_{50}$ being the concentration leading to $50 \%$ cell viability vs. control. Triplicate experiments with triplicate samples were performed. In the experiments, verapamil (10 $\mu \mathrm{M}$; Sigma-Aldrich, Merck Millipore) was used as a positive control agent.

Nude mouse xenograft model and drug administration. A total of 36 male athymic nude mice (BALB/c-nude), 4-5 weeks old and weighing 18-22 g, were obtained from Shanghai SLAC Laboratory Animal Co., Ltd. (Shanghai, China) and used for the MG63/DOX cell xenografts. Mice were housed in an environmentally controlled facility (12:12 h light/dark cycle; $23 \pm 3^{\circ} \mathrm{C}$; humidity of $60 \pm 5 \%$ ) with ad libitum access to chow and water. All experiments swere performed in accordance with the Guidelines for the Welfare of Animals in Experiments (Center of Experimental Animals, China Three Gorges University, China) and all protocols involving animals were approved by the Ethics committee (China Three Gorges University Ethics Committee, Hubei province, China).

The previously established MG63/DOX-inoculated nude xenograft model (18) was used in the current study. The xenograft maintained the MDR phenotype in vivo and was resistant to DOX treatment. In brief, MG63/DOX cells grown in vitro were harvested and subcutaneously injected into the right flank of the nude mice. When the tumor size reached $\sim 150 \mathrm{~mm}^{3}, 24$ mice with approximately the same tumor volume were selected and assigned into four groups $(n=6)$ using a randomized block design based upon their tumor volumes. The four groups were subsequently treated for three days according to the following regimens: i) Saline every third day for 5 doses (q3dx5); ii) Dox [ $5 \mathrm{mg} / \mathrm{kg}$, intravenously (i.v.), q3dx5]; iii) geniposide [100 mg/kg, per os (p.o.), q3dx5]; and iv) Dox (5 mg/kg, i.v., q3dx5)+geniposide $(100 \mathrm{mg} / \mathrm{kg}$, p.o., $\mathrm{q} 3 \mathrm{dx} 5$, given $1 \mathrm{~h}$ prior to injection of Dox). The body weights of the animals and the two perpendicular diameters (A and B) were recorded every three days for 29 days, and tumor volume $(\mathrm{V})$ was estimated according to the following formula: $\mathrm{V}\left(\mathrm{mm}^{3}\right)=(\mathrm{A} \times \mathrm{B})^{2} / 2$; where $\mathrm{V}$ is the tumor volume, $\mathrm{A}$ is the long diameter and $\mathrm{B}$ is the short diameter. Tumor growth curves were drawn according to tumor volume and days post-inoculation. When the maximum tumor volume was $>1,500 \mathrm{~mm}^{3}$, all tumor-bearing mice were sacrificed by cervical dislocation and the tumor tissue was removed and weighed.

Intracellular accumulation of DOX. Intracellular accumulation of DOX in MG63 and MG63/DOX cells. MG63 and MG63/DOX cells $\left(2 \times 10^{5} / 2 \mathrm{ml} /\right.$ well) were seeded in 6-well plates and divided into the following groups: Control, DOX alone $(0.1 \mu \mathrm{M})$, and combined DOX $(0.1 \mu \mathrm{M})$ and geniposide $(100 \mu \mathrm{M})$. At $3 \mathrm{~h}$ after inoculation, cells were incubated with geniposide for $1 \mathrm{~h}$, followed by incubation with $0.1 \mu \mathrm{M}$ DOX for $1 \mathrm{~h}$. Subsequently, cells were washed three times with cold phosphate-buffered saline (PBS) and observed under an Eclipse TE 2000-S fluorescence microscope (Nikon Corporation, Tokyo, Japan).

Intracellular accumulation of Rho123. The difference in the intracellular accumulation of Rho123 between MG63 and MG63/DOX cells and the effect of geniposide on Rho123 uptake were measured by flow cy tometry. Following pre-incubation of the cells with or without $100 \mathrm{mM}$ geniposide for $3 \mathrm{~h}$ at $37^{\circ} \mathrm{C}, 5 \mathrm{mM}$ Rho123 was added and cells were incubated for another $30 \mathrm{~min}$ at $37^{\circ} \mathrm{C}$. Finally, the cells were washed three times with ice-cold PBS and re-suspended in $500 \mathrm{ml}$ PBS prior to flow cytometric analysis (BD FACSCalibur, BD Biosciences, San Jose, CA, USA). A minimum of 10,000 cells were analyzed.

Western blot analysis. The experiment was completed three times. In brief, cells were lysed in Radioimmunoprecipitation assay buffer (cat. no. P0033; Beyotime, Haimen, China) 
following two washes with ice-cold PBS. After $30 \mathrm{mins}$, centrifugation at $13,900 \times g$ was performed and the supernatant was removed. The protein concentration was determined using a bicinchoninic acid assay (cat. no. P0010; Beyotime, Haimen, China). Total cell lysates (30 $\mu \mathrm{g} / \mathrm{lane})$ were separated by $10 \%$ SDS-PAGE and electrotransferred onto polyvinylidene fluoride membranes. Following blocking in 5\% non-fat milk in Tris-buffered saline with Tween 20 for $1 \mathrm{~h}$ at room temperature, membranes were incubated with the primary antibodies against ABCB1 (cat. no. ab3366; dilution, $1: 200)$ at $4^{\circ} \mathrm{C}$ overnight. Immunoblots were incubated with the rabbit anti-mouse immunoglobulin $\mathrm{G}$ conjugated with horseradish peroxidase (cat. no. ab6728; dilution, 1:10,000, Abcam, Ltd.) for $1 \mathrm{~h}$ at room temperature. Membranes were developed using an ECL kit (cat. no. P0018A; Beyotime). The density of the immunoreactive bands was analysed using Image J2x (National Institutes of Health, Bethesda, MD, USA).

Statistical analysis. Values are expressed as the mean \pm standard deviation, unless otherwise stated. All experiments were repeated at least three times and all statistical analyses were performed using SPSS 19.0 software (IBM, SPSS, Inc., Armonk, NY, USA). Differences were determined by one way analysis of variance followed by the Tukey-Kramer multiple comparison test. $\mathrm{P}<0.05$ was considered to indicate a statistically significant difference.

\section{Results}

Geniposide reverses drug resistance of MG63/DOX cells. The drug sensitivities of MG63 and MG63/DOX cells were determined by MTT assays. As presented in Table I, geniposide alone had no significant cytotoxicity $\left(\mathrm{IC}_{50},>200 \mu \mathrm{M}\right)$, causing $<10 \%$ cell death in MG63 and MG63/DOX cells. MG63/DOX cells were 140-fold more resistant to DOX than the native cell line. Various concentrations of geniposide (25, 50 and $100 \mu \mathrm{M}$ ) effectively reversed DOX resistance and sensitized MG63/DOX cells by 4.48-, 13.76- and 31.7-fold, respectively, while verapamil $(10 \mu \mathrm{M})$ achieved a 57.31-fold sensitization. Geniposide had no effects on the DOX sensitivity of parental MG63 cells, while treatment with verapamil $(10 \mu \mathrm{M})$ resulted in a 4.65 -fold sensitization to DOX. These results provide strong in vitro evidence that geniposide effectively reverses DOX resistance of cancer cells.

Geniposide reverses DOX resistance in nude mouse xenografts. The aforementioned in vitro data prompted a further examination into whether geniposide may enhance the in vivo anti-cancer efficacy of DOX in a mouse model with MG63/DOX xenografted tumors. No mortality or apparent decrease in body weight was observed in the combination treatment groups, suggesting that the combination regimen did not increase the incidence of toxic side effects (Fig. 1A). Tumor growth weight curves were constructed and there were no significant differences in tumor size between animals treated with saline, geniposide alone and DOX alone on day 29, indicating the in vivo resistance to DOX (Fig. 1B). However, a significant reduction in tumor volume was observed in mice treated with DOX plus geniposide $(\mathrm{P}<0.05$; Fig. 1C).
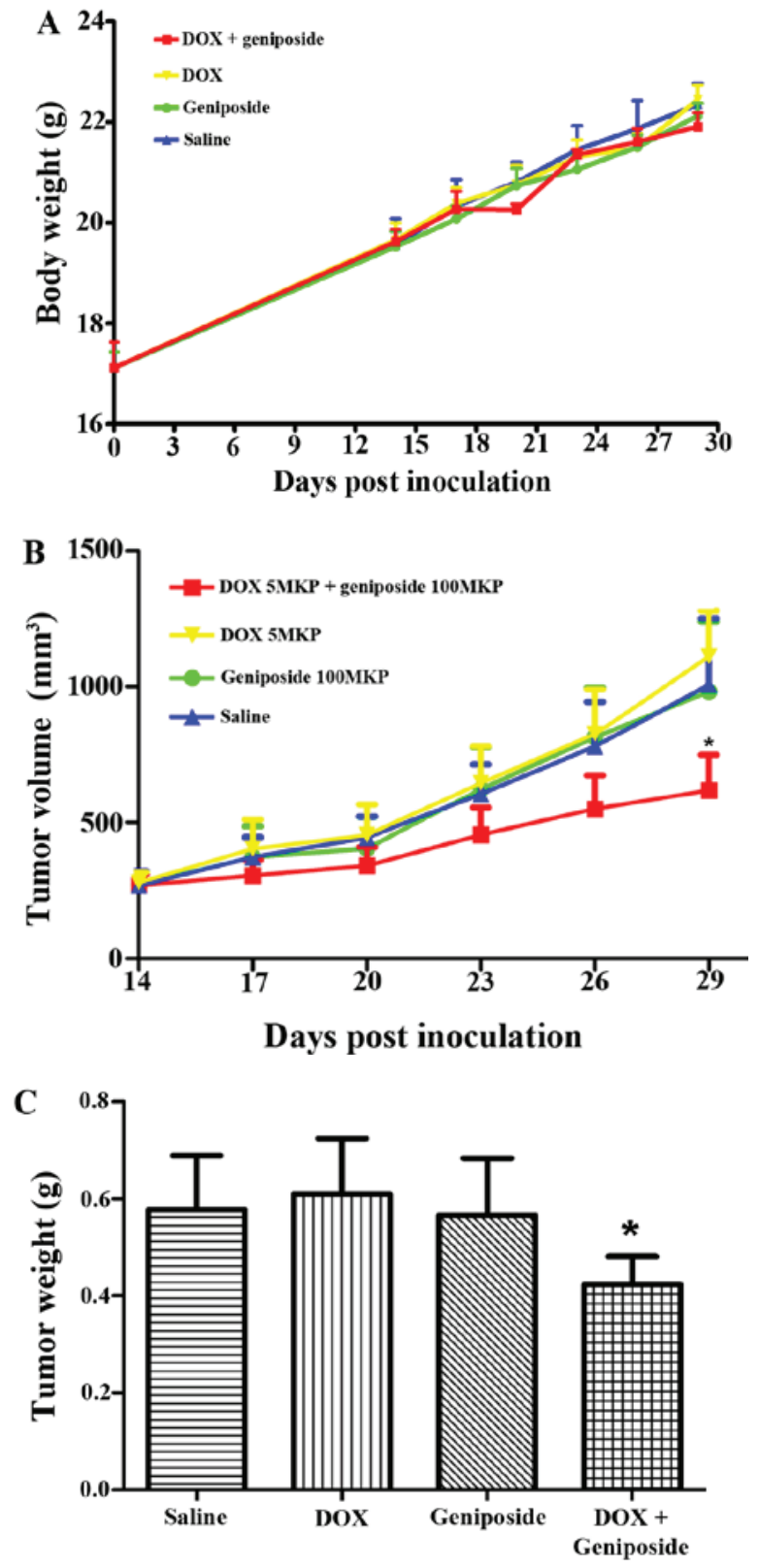

Figure 1. Geniposide enhances the anti-tumor effects of DOX in a xenograft model of MG63/DOX cells in athymic nude mice. (A) Changes in body weight with time following inoculation. Each point represents the mean body weight for each group of 6 mice. Bars represent the standard deviation. (B) Changes in tumor volume with time. Each point represents the mean tumor volume for each group of 6 mice following implantation. Bars represent the standard error of the mean. ${ }^{*} \mathrm{P}<0.05$ compared with saline, DOX and geniposide groups. (C) Tumor weight determined on day 29 following implantation. Columns represent the mean weight for each group of 6 mice. Bars represent the standard deviation. ${ }^{*} \mathrm{P}<0.05$ compared with saline, DOX and geniposide groups. DOX, doxorubicin; MPK, milligrams per kilogram.

Geniposide enhances the accumulation of DOX and Rho123 in MG63/DOX cells. The efflux of anti-cancer drugs from tumor cells into the surrounding tissue decreases intracellular drug concentrations, which may be a major cause of MDR (7). To investigate whether geniposide inhibited the function of P-gp in MG63/DOX cells, the intracellular accumulation of two P-gp substrates, Rho123 and DOX, were measured in the presence and absence of geniposide. P-gp function is known to be correlated with Rho123 and DOX efflux, and 
Table I. Cytotoxicity of DOX and the resistance-reversing effects of geniposide in osteosarcoma cells.

$$
\mathrm{IC}_{50}, \mu \mathrm{mol} / 1 \text { (fold reversal) }
$$

\begin{tabular}{lcc}
\cline { 2 - 3 } Treatment & MG63 & MG63/DOX \\
\hline Geniposide, $\mu \mathrm{M}$ & $>200$ & $>200$ \\
DOX alone & $0.144 \pm 0.00271(1.00)$ & $20.289 \pm 0.00682(1.00)$ \\
DOX+25 $\mu \mathrm{M}$ geniposide & $0.123 \pm 0.00258(1.17)$ & $4.527 \pm 0.00271(4.48)^{\mathrm{b}}$ \\
DOX+50 $\mu \mathrm{M}$ geniposide & $0.128 \pm 0.00372(1.13)$ & $1.475 \pm 0.00271(13.76)^{\mathrm{c}}$ \\
DOX+100 $\mu \mathrm{M}$ geniposide & $0.096 \pm 0.00236(1.5)^{\mathrm{a}}$ & $0.640 \pm 0.00357(31.7)^{\mathrm{d}}$ \\
DOX $+10 \mu \mathrm{M}$ verapamil & $0.031 \pm 0.00295(4.65)^{\mathrm{a}}$ & $0.354 \pm 0.00434(57.31)^{\mathrm{d}}$
\end{tabular}

Values are expressed as the mean \pm standard deviation of at least three independent experiments performed in triplicate. The fold-reversal of multiple drug resistance (values provided in brackets) was calculated by dividing the $\mathrm{IC}_{50}$ for cells with doxorubicin in the absence of geniposide by that obtained in the presence of geniposide. P-gp, P-glycoprotein; IC, measure of toxicity; DOX, doxorubicin; $\mathrm{IC}_{50}$, concentration leading to $50 \%$ growth inhibition. ${ }^{\mathrm{a}} \mathrm{P}<0.05$ compared with DOX alone in MG63 cells; ${ }^{\mathrm{b}} \mathrm{P}<0.05,{ }^{\mathrm{c}} \mathrm{P}<0.01,{ }^{\mathrm{d}} \mathrm{P}<0.005$ compared with DOX alone in MG63/DOX cells.

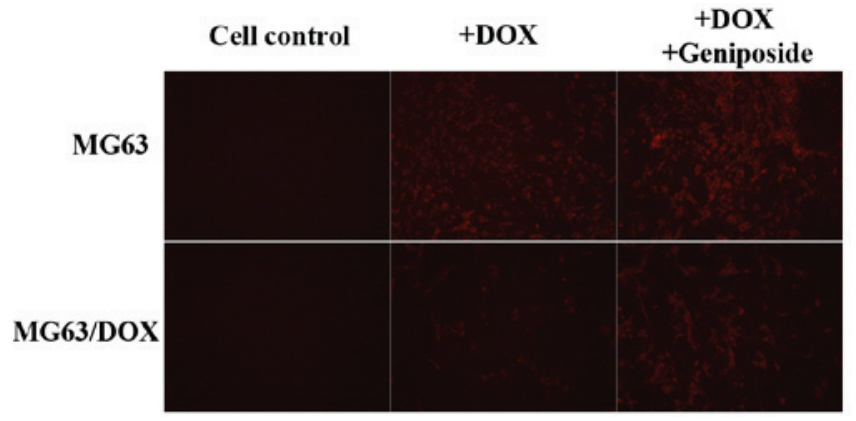

Figure 2. Accumulation of DOX in MG63 and MG63/DOX cells. The cells were incubated with $100-\mu \mathrm{M}$ geniposide at $37^{\circ} \mathrm{C}$ for $3 \mathrm{~h}$, followed by addition of 3- $\mu \mathrm{M}$ DOX and incubation for another hour. The accumulation of DOX was measured by fluorescence microscopy, (magnification, x200). DOX, doxorubicin.

inhibition of $\mathrm{P}-\mathrm{gp}$ results in an increase of the intracellular accumulation of Rho123 and DOX (19). As presented in Fig. 2, $100 \mu \mathrm{M}$ geniposide increased the intracellular accumulation of DOX in MG63/DOX cells, whereas in MG63 cells, there was no significant alteration in the intracellular accumulation of DOX between cells treated with DOX+geniposide and those treated with DOX alone. Furthermore, the intracellular accumulation of Rho123 significantly differed between MG63 and MG63/DOX cells ( $\mathrm{P}<0.01$; Fig. 3A). In the presence of $100 \mu \mathrm{M}$ geniposide, the intracellular accumulation of Rho123 was increased in MG63/DOX cells, with an increase in fluorescence intensity from 43.48-101.21; a 2.33-fold increase $(\mathrm{P}<0.05$; Fig. 3B). These results suggested that geniposide significantly enhances the accumulation of P-gp substrates in MG63/DOX cells.

Geniposide decreases $P$-gp protein expression within MG63/DOX cells. In addition to competitive inhibition of drug efflux, reversal of P-gp-mediated MDR may be achieved by decreasing P-gp protein expression (20). Therefore, the effects of geniposide on the expression of $\mathrm{P}$-gp in MG63/DOX cells were assessed. Treatment with 50 and $100 \mu \mathrm{M}$ geniposide for $72 \mathrm{~h}$ significantly decreased
P-gp expression in a dose dependent manner ( $\mathrm{P}<0.05$; Fig. 4). These results suggest that reduced expression of $\mathrm{P}-\mathrm{gp}$ is involved in geniposide-associated reversal of $\mathrm{P}$-gp-mediated MDR.

\section{Discussion}

MDR is a prevalent issue in cancer chemotherapy. Reversing MDR in cancer cells may be a method of overcoming drug resistance and improving the efficacy of chemotherapy and thus, the outcome of patients with cancer. The primary mechanism leading to the development of the MDR phenotype is the overexpression of P-gp drug efflux transporters (5). P-gp has a broad spectrum of substrates with a variety of structures and different molecular mechanisms of drug action, including DOX, paclitaxel and vincristine. As a result, it is easy to filter out their inhibitors in vitro. Over the past three decades, three generations of reversal agents have been identified, including verapamil, cyclosporine A and valspodar. However, to date, no single compound or composition has been approved for clinical use. Screening for P-gp inhibitors continues with the aim of identifying a reversal agent that is non-toxic and possesses a $\mathrm{P}$-gp-specific binding ability that does not affect drug distribution and excretion in vivo when used in combination with chemotherapy drugs. Due to their low toxicity, natural products from Traditional Chinese Medicine are now becoming the focus of multiple studies. A series of promising compounds, including curcumin (21) and tetrandrine (22), have been identified.

It has previously been demonstrated that geniposide, one of the major iridoid glycosides of the gardenia fruit, exhibits activity against the tumor-promoting factor 2-O-tetradecanoylphorbol-13-acetate, which activates protein kinase $C$ (23). In the present study, the inhibitory and sensitizing effects of geniposide in cells overexpressing P-gp were investigated. The results indicated that geniposide potently reversed $\mathrm{P}$-gp-mediated MDR in vitro. As demonstrated by the MTT assay, the working concentrations of geniposide selected to study the MDR reversal effect were only weakly cytotoxic (inhibition rate $<10 \%$ ). Geniposide 
A

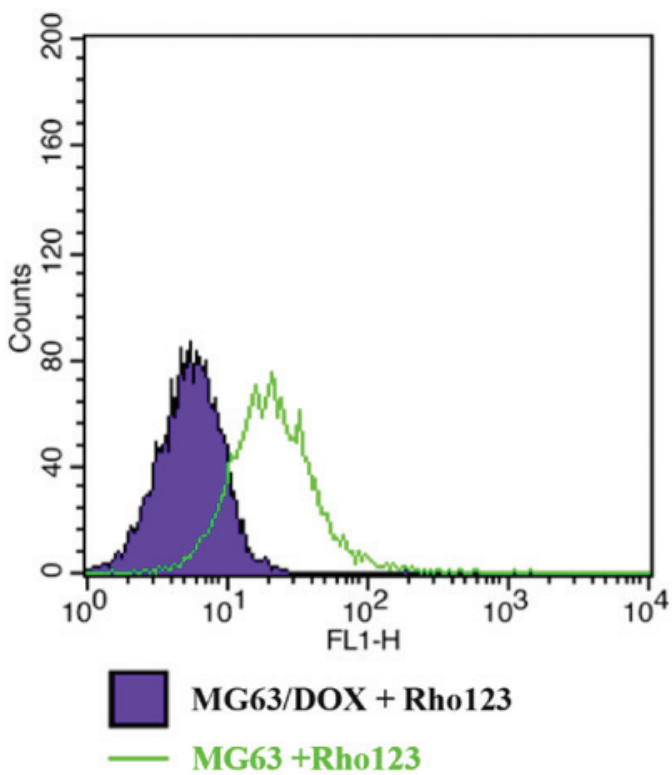

B

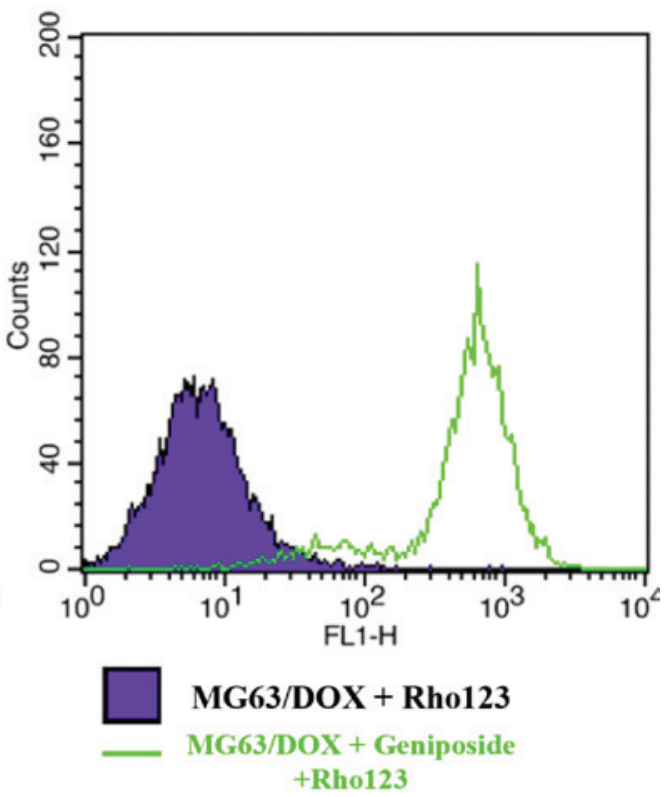

Figure 3. Accumulation of Rho123 in MG63 and MG63/DOX cells. Flow cytometric analysis indicated that the intracellular accumulation of Rho123 in MG63/DOX cells was (A) markedly lower than that in the native MG63 cells $(\mathrm{P}<0.01)$ and (B) significantly increased in the presence of $100 \mu$ M geniposide $(\mathrm{P}<0.05)$. Experiments were performed at least three times and representative results of one experiment are shown. Rho123, rhodamine 123; DOX, doxorubcin.
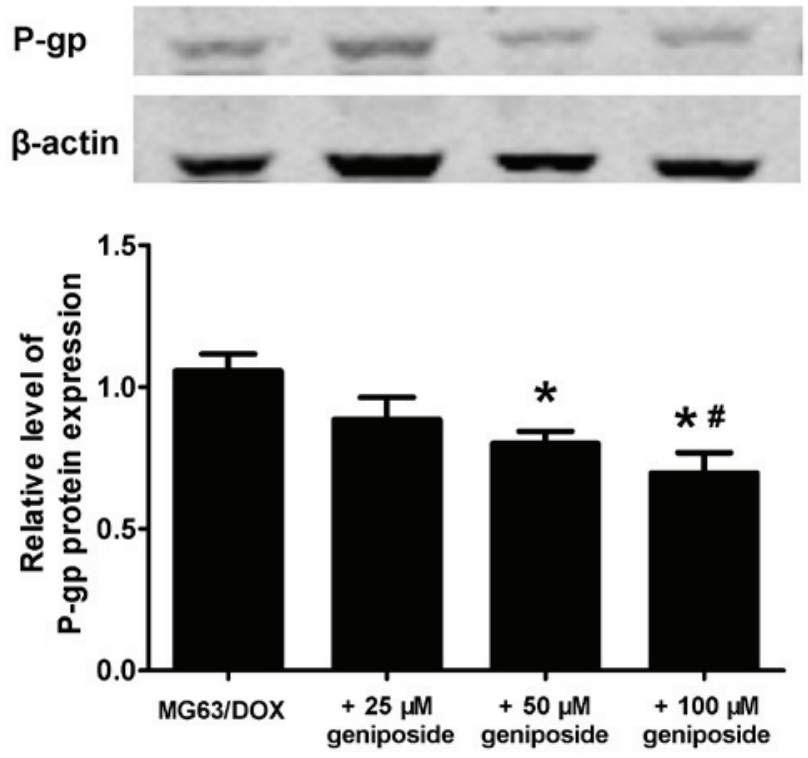

Figure 4. Western blot analysis of P-gp in MG63/DOX cells following treatment with 25,50 and $100 \mu \mathrm{M}$ geniposide. An image representative of three experiments is presented. Columns indicate the mean value $(n=3)$ and bars represent the standard deviation. Results from western blotting were quantified and expressed as the relative ratio of $\mathrm{P}-\mathrm{gp} / \beta$-Actin intensity, and the mean value of ratio of $\mathrm{P}$-gp/ $\beta$-Actin in MG63/DOX group returned to 1. ${ }^{*} \mathrm{P}<0.05$ compared with control group; ${ }^{\#} \mathrm{P}<0.05$ compared with the $25 \mu \mathrm{M}$ geniposide group. P-gp, P-glycoprotein.

at $100 \mathrm{mM}$ increased the sensitivity of MG63/DOX cells to DOX 31.7-fold. However, geniposide did not significantly sensitize the corresponding parental MG63 cells.

To determine whether the in vitro effects of geniposide also occur in an in vivo setting, the effect of geniposide on the anti-tumor activity of DOX in an ABCB1-overexpressing MG63/DOX-inoculated xenograft model was examined. The results indicated that the combination of geniposide and doxorubicin resulted in a marked increase in the anti-tumor activity of DOX in the xenograft model. Furthermore, there was no marked decrease in the body weight of mice treated with geniposide and DOX compared to those treated with either drug alone. These results indicated that in the xenograft model of ABCB1-overexpressing MG63/DOX cells, geniposide markedly enhanced the anti-tumor activity of DOX.

The inhibition of P-gp may occur at the level of biosynthesis and activity (24). Therefore, P-gp-mediated drug transport activity was assessed in order to investigate the mechanisms by which geniposide inhibited P-gp-induced MDR. Consistent with the cytotoxicity data, it was determined that geniposide significantly $(\mathrm{P}<0.05)$ increased the intracellular accumulation of DOX and Rho123 in P-gp-overexpressing MDR cells in a dose-dependent manner. The possible regulation of $\mathrm{P}-\mathrm{gp}$ expression by geniposide was examined at the protein level and the results indicated that $50-100 \mu \mathrm{M}$ geniposide significantly downregulated P-gp expression in MG63/DOX cells.

In conclusion, to the best of our knowledge the present study was the first to provide evidence that geniposide significantly enhances the efficacy of a chemotherapeutic drug in $\mathrm{P}$-gp-overexpressing MDR cells. This may be due to the competitive inhibition of the transport function as well as a decrease in the expression of P-gp protein. Of note, confirmation of MDR reversal by geniposide in the tumor xenograft model suggests that geniposide may be combined with other conventional anti-cancer drugs to combat or prevent MDR during cancer chemotherapy. Thus, the findings of the present study indicated that geniposide may be a candidate agent for reversing MDR in cancer, which requires confirmation by further studies. 


\section{Acknowledgements}

The authors would like to thank Dr Zan Shen (Department of Oncology, Affiliated Sixth People's Hospital, Shanghai Jiao Tong University, Shanghai, China) for kindly providing the MG63/DOX cell line. The present study was supported by the Foundation of Hubei Province Natural Science Fund (no. 2012FFB06302).

\section{References}

1. Kathawala RJ, Gupta P, Ashby CR Jr and Chen ZS: The modulation of $\mathrm{ABC}$ transporter-mediated multidrug resistance in cancer: A review of the past decade. Drug Resist Updat 18: 1-17, 2015.

2. Holohan C, Van Schaeybroeck S, Longley DB and Johnston PG: Cancer drug resistance: An evolving paradigm. Nat Rev Cancer 13: 714-726, 2013.

3. Gottesman MM, Fojo T and Bates SE: Multidrug resistance in cancer: Role of ATP-dependent transporters. Nat Rev Cancer 2: $48-58,2002$

4. Juliano RL and Ling V: A surface glycoprotein modulating drug permeability in Chinese hamster ovary cell mutants. Biochim Biophys Acta 455: 152-162, 1976.

5. Choi $\mathrm{YH}$ and $\mathrm{Yu} \mathrm{AM}$ : $\mathrm{ABC}$ transporters in multidrug resistance and pharmacokinetics and strategies for drug development. Curr Pharm Des 20: 793-807, 2014

6. Choi $\mathrm{CH}$ : $\mathrm{ABC}$ transporters as multidrug resistance mechanisms and the development of chemosensitizers for their reversal. Cancer Cell Int 5: 30, 2005.

7. Ozben T: Mechanisms and strategies to overcome multiple drug resistance in cancer. FEBS Lett 580: 2903-2909, 2006.

8. Borst P, Evers R, Kool M and Wijnholds J: A family of drug transporters: The multidrug resistance-associated proteins. J Natl Cancer Inst 92: 1295-1302, 2000.

9. Su S, Cheng X and Wink M: Natural lignans from Arctium lappa modulate P-glycoprotein efflux function in multidrug resistant cancer cells. Phytomedicine 22: 301-307, 2015.

10. Liu J, Yin F, Zheng X, Jing J and Hu Y: Geniposide, a novel agonist for GLP-1 receptor, prevents PC12 cells from oxidative damage via MAP kinase pathway. Neurochem Int 51: 361-369, 2007.

11. Liu JH, Yin F, Guo LX, Deng XH and Hu YH: Neuroprotection of geniposide against hydrogen peroxide induced $\mathrm{PC} 12$ cells injury: Involvement of PI3 kinase signal pathway. Acta Pharmacol Sin 30: 159-165, 2009.

12. Koo HJ, Lim KH, Jung HJ and Park EH: Anti-inflammatory evaluation of gardenia extract, geniposide and genipin. J Ethnopharmacol 103: 496-500, 2006.
13. Ma TT, Li XF, Li WX, Yang Y, Huang C, Meng XM, Zhang L and $\mathrm{Li} \mathrm{J}$ : Geniposide alleviates inflammation by suppressing $\mathrm{MeCP} 2$ in mice with carbon tetrachloride-induced acute liver injury and LPS-treated THP-1 cells. Int Immunopharmacol 29: 739-747, 2015.

14. Suzuki Y, Kondo K, Ikeda Y and Umemura K: Antithrombotic effect of geniposide and genipin in the mouse thrombosis model. Planta Med 67: 807-810, 2001.

15. Guo-liang S, Xiao L, Fu-Jun S and Gui-Hua L: Study on the flavonoid of Huanglian Jiedu decoction in reversing MDR of K562/ADM. Chinese Journal of Experimental Traditional Medical Formulae 18: 217-219, 2012.

16. Xiao L, Guoliang S, Fujun S and Guihai S: Influence of flavonoids ingredients extract from Huanglianjiedu Decoction on expression of K562/ADM cells multidrug resistance related gene. Pharmacology and Clinics of Chinese Materia Medica 28: 20-24, 2012.

17. Yuan D, Wan JZ, Deng LL, Zhang CC, Dun YY, Dai YW, Zhou ZY, Liu CQ and Wang T: Chikusetsu saponin V attenuates $\mathrm{MPP}^{+}$-induced neurotoxicity in SH-SY5Y cells via regulation of Sirt1/Mn-SOD and GRP78/caspase-12 pathways. Int J Mol Sci 15: 13209-13222, 2014.

18. Zhou Z, Wan L, Han Y, Meng X, Yang Q, Li Y, Yu Q, Shen Z and Guo C: ABCB1-overexpressing MG63/DOX cell xenograft model: Maintain the MDR phenotype in vivo. Pharm Biol 51: 968-973, 2013.

19. Mi YJ, Liang YJ, Huang HB, Zhao HY, Wu CP, Wang F, Tao LY, Zhang CZ, Dai CL, Tiwari AK, et al: Apatinib (YN968D1) reverses multidrug resistance by inhibiting the efflux function of multiple ATP-binding cassette transporters. Cancer Res 70: 7981-7991, 2010

20. Wang J, Liu L, Cen J and Ji B: BME, a novel compound of anthraquinone, down regulated P-glycoprotein expression in doxorubicin-resistant human myelogenous leukemia (K562/DOX) cells via generation of reactive oxygen species. Chem Biol Interact 239: 139-145, 2015.

21. Chearwae W, Anuchapreeda S, Nandigama K, Ambudkar SV and Limtrakul P: Biochemical mechanism of modulation of human P-glycoprotein (ABCB1) by curcumin I, II, and III purified from Turmeric powder. Biochem Pharmacol 68: 2043-2052, 2004.

22. Sun YF and Wink M: Tetrandrine and fangchinoline, bisbenzylisoquinoline alkaloids from Stephania tetrandra can reverse multidrug resistance by inhibiting P-glycoprotein activity in multidrug resistant human cancer cells. Phytomedicine 21: 1110-1119, 2014.

23. Lee MJ, Hsu JD and Wang CJ: Inhibition of 12-O-tetradecanoylphorbol-13-acetate-caused tumor promotion in benzo [a]pyrene-initiated CD-1 mouse skin by geniposide. Anticancer Res 15: 411-416, 1995.

24. Varma MV, Ashokraj Y, Dey CS and Panchagnula R: P-glycoprotein inhibitors and their screening: A perspective from bioavailability enhancement. Pharmacol Res 48: 347-359, 2003. 